\title{
Decreased Plasma Octanoylated Ghrelin Levels in Mice by Oleanolic Acid
}

\author{
Kensuke Nakajima1, Narumi Maeda', Shigeru Oiso ${ }^{1,2}$, and Hiroko Kariyazono ${ }^{1,2 *}$ \\ ${ }^{1}$ Department of Pharmacy, Faculty of Pharmaceutical Sciences, Nagasaki International University, 2825-7 Huis Ten Bosch, Sasebo, Nagasaki \\ 859-3298, JAPAN \\ ${ }^{2}$ Graduate School of Pharmaceutical Sciences, Nagasaki International University, 2825-7 Huis Ten Bosch, Sasebo, Nagasaki 859-3298, JAPAN
}

\begin{abstract}
Ghrelin is a stomach-derived peptide hormone with an appetite-stimulating effect. Octanoylation on the serine-3 residue of ghrelin by ghrelin $O$-acyl transferase (GOAT) is essential for its orexigenic effect. Mature octanoylated ghrelin is generated by the $\mathrm{C}$-terminal cleavage of octanoylated proghrelin via prohormone convertases (furin, PC1/3, or PC2). We previously established an AGS-GHRL8 cell line that produces octanoylated ghrelin in the presence of octanoic acid, and found that oleanolic acid suppresses octanoylated ghrelin production in AGS-GHRL8 cells. Here, we investigated the effects of oleanolic acid in C57BL/6J mice fed a standard, high-fat, or high-glucose diet. Oral administration of oleanolic acid for seven days $(20$ or $40 \mathrm{mg} / \mathrm{kg}$ ) reduced plasma octanoylated ghrelin levels and body weight gain in the standard dietfed mice but not in other two diet-fed mice. There were no significant differences in ghrelin, GOAT, furin, PC1/3, and PC2 gene expression levels between the vehicle- and oleanolic acid-treated mice fed a standard diet. Octanoyl-CoA is a substrate for ghrelin octanoylation by GOAT. We found that oleanolic acid did not affect octanoyl-CoA production in vitro. Hence, the inhibitory effect of oleanolic acid on octanoylated ghrelin production may not be related to the decrease in octanoyl-CoA. The results of this study may provide valuable knowledge for the development of anti-obesity agents with an inhibitory effect on octanoylated ghrelin production.
\end{abstract}

Key words: oleanolic acid, octanoylated ghrelin, anti-obesity, C57BL/6J mouse

\section{INTRODUCTION}

Ghrelin is a 28 -amino-acid peptide hormone initially identified in the rat stomach that acts as an endogenous ligand for the growth hormone secretagogue receptor ${ }^{1)}$. Ghrelin circulates in the blood as two main isoforms: octanoylated ghrelin and des-acyl ghrelin ${ }^{2}$. Octanoylated ghrelin, the active form, stimulates appetite and induces body weight gain, whereas des-acyl ghrelin, which has no acyl modification, does not have these activities ${ }^{3)}$. Furthermore, octanoylated ghrelin decreases energy expenditure by decreasing oxygen consumption and suppressing thermogenesis in brown adipose tissue ${ }^{4-6)}$. Therefore, lowering plasma octanoylated ghrelin levels may be an important strategy for the prevention and treatment of obesity.

The conversion of the proghrelin precursor to octanoylated ghrelin involves two steps, i.e., octanoylation at the serine- 3 residue, which is catalyzed by ghrelin $O$-acyl transferase $(\mathrm{GOAT})^{7-9)}$, and cleavage by prohormone convertases $(\mathrm{PC})$, such as furin, $\mathrm{PC} 1 / 3$, or $\mathrm{PC} 2^{10,11)}$. In ghrelin octanoylation, octanoyl-CoA is a substrate for GOAT. Oc-
tanoyl-CoA is formed by the dehydrocondensation of the carboxy group in octanoic acid and the thiol group in CoA.

We previously identified inhibitors of octanoylated ghrelin production using the ghrelin-expressing cell line AGS-GHRL8 developed in our laboratory ${ }^{12)}$. Using a cell based assay system, we found that oleanolic acid (Fig. 1), a triterpene contained in plants, such as grapes (Vitis vinifera), pomegranate (Punica granatum), and olive (Olea europaea), reduces octanoylated ghrelin levels in AGSGHRL8 cells ${ }^{13)}$. Furthermore, $\beta$-amylin, a compound in which the carboxy group of oleanolic acid is substituted with a methyl group, does not inhibit octanoyl ghrelin production in AGS-GHRL8 cells and the carboxy group in oleanolic acid is crucial for the inhibition of octanoylated ghrelin production ${ }^{13)}$.

In this study, we investigated whether the oral administration of oleanolic acid affects plasma octanoylated ghrelin levels, food intake, and body weight gain in C57/BL6J mice fed a standard, high-fat, or high-glucose diet. In addition, we evaluated the mRNA levels of ghrelin, GOAT, and PCs

\footnotetext{
*Correspondence to: Hiroko Kariyazono, Graduate School of Pharmaceutical Sciences, Nagasaki International University, 2825-7 Huis Ten Bosch, Sasebo, Nagasaki 859-3298, JAPAN

E-mail: karihiro@niu.ac.jp

Accepted October 22, 2018 (received for review July 26, 2018)

Journal of Oleo Science ISSN 1345-8957 print / ISSN 1347-3352 online

http://www.jstage.jst.go.jp/browse/jos/ http://mc.manusriptcentral.com/jjocs
} 


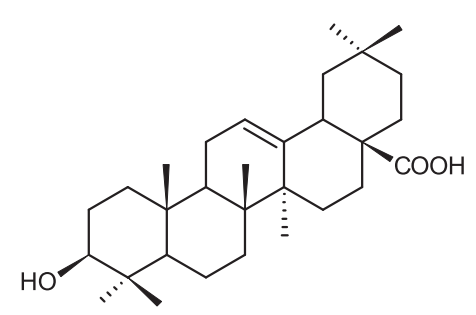

Fig. 1 Chemical structure of oleanolic acid.

in mice treated with oleanolic acid and investigated whether oleanolic acid inhibits the production of octanoylCoA in vitro.

\section{EXPERIMENTAL}

\subsection{Reagents and materials}

Oleanolic acid was purchased from Tokyo Chemical Industry Co. (Tokyo, Japan). Glucose and hydroxyethyl cellulose were obtained from Wako Pure Chemical Industries (Osaka, Japan). The Acylated Ghrelin(mouse, rat) Express EIA Kit was purchased from Bertin Pharma(Montigny le Bretonneux, France). The Free Fatty Acid Assay Kit was obtained from Cell Biolabs, Inc. (San Diego, CA, USA). RNAlater and TRIzol reagents were obtained from Life Technologies (Carlsbad, CA, USA), and ReverTra Ace was purchased from Toyobo (Osaka, Japan). SYBR ${ }^{\circledR}$ Fast qPCR Mix was purchased from Takara Bio Inc. (Ohtsu, Japan). Primers targeting ghrelin, GOAT, furin, PC1/3, PC2, and $18 \mathrm{~S}$ ribosomal RNA were synthesized by Genenet (Fukuoka, Japan) and Greiner Japan (Kanagawa, Japan). Other reagents were obtained from Wako Pure Chemical Industries unless otherwise indicated.

\subsection{Animals and experimental treatment}

Male 6-week-old C57BL/6J mice were purchased from SLC (Shizuoka, Japan). The mice were housed in an aircontrolled room $\left(25 \pm 2{ }^{\circ} \mathrm{C}\right.$ and $50 \%$ humidity $)$ with a 12-hour light/dark cycle(7:00/19:00). The mice were fed a standard diet (CE-2, Clea Japan, Tokyo, Japan) and water ad libitum for 1 week prior to experiments.

The mice were assigned to three groups matched according to body weight: vehicle (0.5\% hydroxyethyl cellulose solution), $20 \mathrm{mg} / \mathrm{kg}$ oleanolic acid, and $40 \mathrm{mg} / \mathrm{kg}$ oleanolic acid. Oleanolic acid was suspended in $0.5 \%$ hydroxyethyl cellulose solution. Vehicle $(0.5 \%$ hydroxyeth- yl cellulose solution) or oleanolic acid was administered by oral gavage once a day at 13:00 for 7 days. The body weight of each mouse was monitored every day, and the cumulative food intake during the experiment period was measured. On day 7 , after the final administration, the mice were fasted for $6 \mathrm{~h}$, and blood and the stomach were collected under anesthesia with a mixture of medetomidine, midazolam and butorphanol. Plasma was collected by centrifugation from the blood samples at $2,000 \times g$ for $5 \mathrm{~min}$, mixed with a $1 / 10$ volume of $1 \mathrm{~mol} / \mathrm{L} \mathrm{HCl}$, and stored at $-80^{\circ} \mathrm{C}$ until analysis. Plasma octanoylated ghrelin concentrations were measured using the Acylated Ghrelin(mouse, rat) Express EIA Kit according to the manufacturer's instructions. Animal studies were repeated using mice fed a high-fat diet(D12451; Research Diets, New Brunswick, NJ, USA) or a high-glucose diet composed of CE-2 and glucose at a weight ratio of 3:2. The proportion of protein, carbohydrate, and fat contained in the standard diet (CE-2) and the high-fat diet(D12451) is shown in Table 1. Furthermore, the compositions of fatty acid in these two diets are shown in Table 2.

The animal studies were approved by the Research Ethics Committee of the Faculty of Pharmaceutical Sciences of Nagasaki International University (No. 126) and were conducted in accordance with Ethical Guidelines for Animal Experiments of the Faculty of Pharmaceutical Sciences of Nagasaki International University.

\subsection{Quantitative reverse transcription-polymerase chain reaction ( $q R T-P C R$ )}

To study the mechanism by which oleanolic acid inhibits octanoylated ghrelin production, mRNA levels of mouse ghrelin, GOAT, furin, PC1/3, and PC2 in the stomach tissues were evaluated by qRT-PCR. Total RNA was extracted from each mouse stomach using TRIzol reagent and reverse-transcribed into cDNA using ReverTra Ace. PCR was performed using the CFX Connect Real-Time System(Bio-Rad, Tokyo, Japan). The reaction mixture containing $10 \mu \mathrm{L}$ of $2 \times \mathrm{SYBR}^{\circledR}$ Fast qPCR Mix, $0.4 \mathrm{pmol}$ sense and antisense primers, and $2 \mu \mathrm{L}$ of diluted cDNA was loaded onto a 96 -well plate. Amplification was performed under the following conditions: $95^{\circ} \mathrm{C}$ for $30 \mathrm{~s}$, followed by 40 cycles of $95^{\circ} \mathrm{C}$ for $5 \mathrm{~s}$ and $60^{\circ} \mathrm{C}$ for $10 \mathrm{~s}$. The sense and antisense primers used in this study are shown in Table 3. Transcript levels were estimated from the respective standard curves and normalized to the levels of $18 \mathrm{~S}$ ribosomal

Table 1 Standard diet (CE-2) and high-fat diet(D12451) components used in this study.

\begin{tabular}{lcccc}
\hline Diet & Protein (g\%) & Carbohydrate (g\%) & Fat (g\%) & Others $(\mathbf{g} \%)$ \\
\hline Standard-diet (CE-2) & 25 & 50 & 5 & 20 \\
High-fat diet (D12451) & 24 & 41 & 24 & 11 \\
\hline
\end{tabular}


Table 2 Fatty acid components in CE-2 and D12451.

\begin{tabular}{lcc}
\hline & \multicolumn{2}{c}{ Content } \\
Ingredient & (g\% of total fatty acids) \\
\cline { 2 - 3 } & CE-2 & D12451 \\
\hline Myristic (14:0) & 1 & 1 \\
Palmitic (16:0) & 16 & 19 \\
Palmitoleic (16:1) & 1 & 1 \\
Stearic (18:0) & 2 & 10 \\
Oleic (18:1) & 21 & 34 \\
Linoleic (18:2) & 44 & 30 \\
Others & 15 & 5 \\
\hline
\end{tabular}

Table 3 The primers used in this study.

\begin{tabular}{|c|c|}
\hline Gene & Primer pairs \\
\hline Ghrelin & $\begin{array}{l}\text { 5'-GAAGCCACCAGCTAAACTGC-3' } \\
\text { 5'-GCCATGCTGCTGATACTGAG-3' }\end{array}$ \\
\hline GOAT & $\begin{array}{l}\text { 5'-ACAGCTCTGTGGCTCAGGAG-3' } \\
\text { 5'-GGCTTCACCATTACAGACC-3' }\end{array}$ \\
\hline Furin & $\begin{array}{l}\text { 5'-GAAGTGCACAGAATCTCACA-3' } \\
\text { 5'-GCCAGGTGAGGTTCTTGTTG-3' }\end{array}$ \\
\hline $\mathrm{PC} 1 / 3$ & $\begin{array}{l}\text { 5'-TCTITGCTCTGGCCTTGGAG-3' } \\
\text { 5'-ACCTGGGTTACTGGCCAATG-3' }\end{array}$ \\
\hline PC2 & $\begin{array}{l}\text { 5'-AGACAATGGGAAGACGGTTG-3' } \\
\text { 5'-CCAGAGGCCCACACATAGAT-3' }\end{array}$ \\
\hline $18 \mathrm{~S} \mathrm{rF}$ & $\begin{array}{l}\text { 5'-GTAACCCGTTGAACCCCATT-3' } \\
\text { 5'-CCATCCAATCGGTAGTAGCG-3' }\end{array}$ \\
\hline
\end{tabular}

RNA.

\subsection{Evaluation of the effect of oleanolic acid on octanoyl CoA production}

The Free Fatty Acid Assay Kit was used to evaluate the effect of oleanolic acid on octanoyl-CoA production by measuring the amount of free fatty acids using acyl-CoA synthetase and acyl-CoA oxidase. First, acyl-CoA synthetase catalyzes the fatty acid acylation of CoA. Next, the acyl-CoA product is oxidized by acyl-CoA oxidase, producing hydrogen peroxide which reacts with the colorimetric probe (absorbance of $570 \mathrm{~nm}$ ) included in the kit. Accordingly, the amount of a conjugation between fatty acid and CoA is determined by $570 \mathrm{~nm}$. Octanoic acid $(100 \mu \mathrm{mol} / \mathrm{L})$, oleanolic acid $(100 \mu \mathrm{mol} / \mathrm{L})$, or a combination of both compounds was added to a 96-well plate. The assay was performed according to the manufacturer's instructions, and absorbance at $570 \mathrm{~nm}$ was determined for each well.

\subsection{Statistical analysis}

Data are presented as means \pm standard deviation $(\mathrm{SD})$. Differences among groups were analyzed by ANOVA, followed by Tukey's tests for multiple comparisons. Differences were considered significant at $p<0.05$.

\section{RESULTS}

3.1 Effects of oleanolic acid on plasma octanoylated ghrelin levels, cumulative food intake, and body weight gain

Compared to the vehicle group, oleanolic acid (20 and 40 $\mathrm{mg} / \mathrm{kg}$ ) significantly reduced plasma octanoylated ghrelin levels and body weight gain $(p<0.05)$ in the standard dietfed mice (Fig. 2A). Food intake was lower in the oleanolic acid-treated groups than in the vehicle-treated group, but this difference was not significant (Fig. 2A).

In contrast to the observed effects in standard diet-fed mice, oleanolic acid had no effects on octanoylated ghrelin levels, cumulative food intake, or body weight gain in highfat or high-glucose diet-fed mice (Fig. 2B, 2C).

3.2 Effects of oleanolic acid on ghrelin, GOAT, furin, PC1/3, and PC2 mRNA expression

We investigated whether gene expression changes contribute to the decreased levels of octanoylated ghrelin in the plasma. In particular, we examined the expression of genes encoding ghrelin, GOAT, and PCs involved in ghrelin processing in the stomachs of standard diet-fed mice by qRT-PCR. Oleanolic acid (20 or $40 \mathrm{mg} / \mathrm{kg}$ ) had no significant effect on the relative mRNA expression levels of ghrelin, GOAT, furin, PC1/3, and PC2 (Fig. 3).

\subsection{Effect of oleanolic acid on octanoyl CoA production}

We previously showed that the carboxy group mediates the effect of oleanolic acid on octanoylated ghrelin levels ${ }^{13)}$. Octanoyl-CoA, a substrate for the octanoylation of ghrelin by GOAT, is formed by the dehydrocondensation of the octanoic acid carboxy group and CoA thiol group. Therefore, we hypothesized that the binding of oleanolic acid with a carboxy group to CoA may cause a competitive decrease in the production of octanoyl-CoA and reduced levels of octanoylated ghrelin. Hence, we investigated whether oleanolic acid inhibits the production of octanoyl-CoA using the Free Fatty Acid Assay Kit. In the assay, the absorbance of the reaction mixture increases as a complex with CoA is formed. A significant increase in absorbance was observed when octanoic acid was added(Fig. 4). Absorbance in the wells treated with oleanolic acid was nearly identical to that in the control(Fig. 4). The addition of octanoic acid and combined addition of octanoic acid and oleanolic acid resulted in similar increases in absorbance(Fig. 4). 

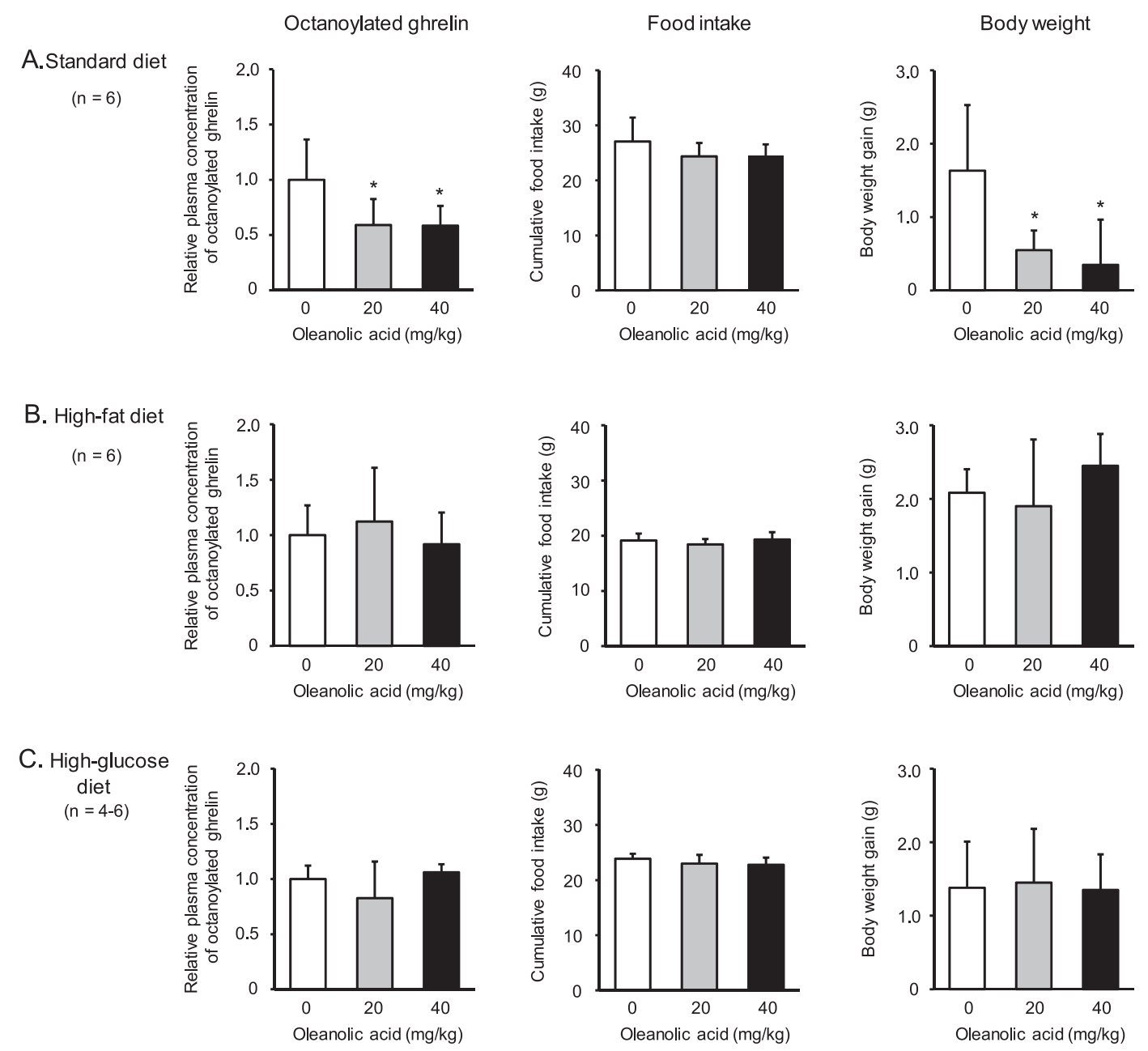

Fig. 2 Effects of oleanolic acid on standard (A), high-fat (B), or high-glucose diet-fed mice (C). The ratio of octanoylated ghrelin concentrations to vehicle (left graph), cumulative food intake for 7 days (middle graph) and body weight gain for 7 days (right graph) are presented. Each value represents the mean $\pm \mathrm{SD}(\mathrm{n}=4-6) . * p<0.05$ vs. the vehicle group (white bar).

\section{DISCUSSION}

Oleanolic acid has anti-obesity effects in mice ${ }^{14)}$. In the present study, we found that the oral administration of oleanolic acid significantly decreases plasma octanoylated ghrelin levels and body weight gain without altering cumulative food intake in standard diet-fed mice. There are two noteworthy points regarding these results. First, despite the reduction in plasma octanoylated ghrelin levels, oleanolic acid had no effect on cumulative food intake. Wellman et al. reported that the intraperitoneal injection of a GOAT inhibitor once a day for 4 days decreased food intake for the initial $1 \mathrm{~h}$ after re-feeding in $24 \mathrm{~h}$-fasted mice ${ }^{15)}$; however decreased food intake was not observed after $2 \mathrm{~h}$. These results suggest that the inhibitory effect of decreased octanoylated ghrelin on food intake disappeared over a short period of time. In our study, since the observation period for cumulative food intake was 7 days and mice were not fasted during the period, a decrease in cumulative food consumption may not be detected. In addition, experimental and clinical studies have indicated that the blood concentration of oleanolic acid decreases within several hours after its administration ${ }^{16-18)}$. Therefore, the oncedaily administration of oleanolic acid may be insufficient to maintain a low level of octanoylated ghrelin throughout the day.

The second point is that oleanolic acid significantly reduced body weight gain in standard-diet fed mice, despite the lack of a difference in cumulative food intake. Octanoylated ghrelin reduces energy expenditure ${ }^{4-6)}$; therefore, increased energy expenditure induced by the reduction of octanoylated ghrelin levels may explain the decreased body weight gain.

Previously, de Melo et al. reported that oleanolic acid (10 $\mathrm{mg} / \mathrm{kg}$ for 15 weeks) decreased plasma ghrelin levels and body weight gain in mice ${ }^{14}$. The administration period of their study is much longer but dosage is smaller than those 


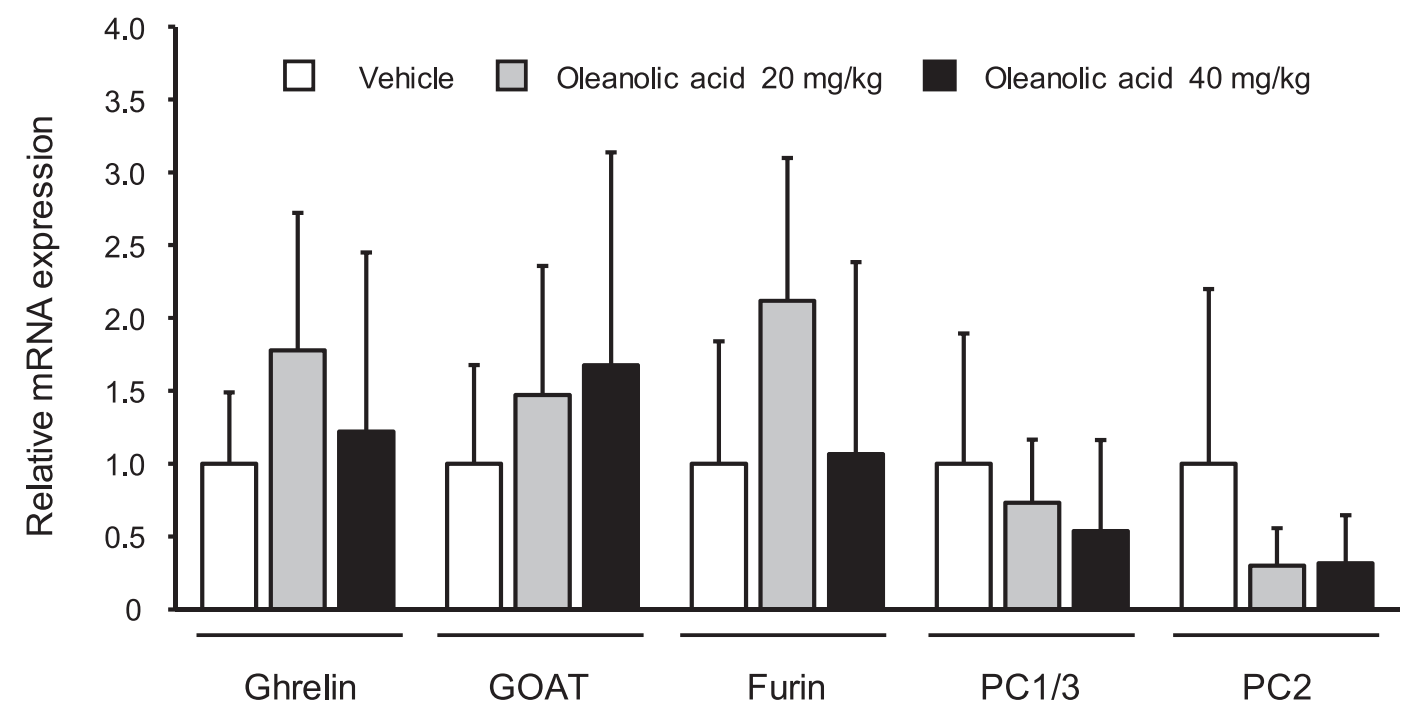

Fig. 3 Effects of oleanolic acid on the mRNA expression of ghrelin, GOAT, furin, PC1/3, and PC2 in stomach tissues collected from standard diet-fed mice. Data are presented as mRNA expression levels relative to levels in the vehicle groups. Values represent means $\pm \mathrm{SD}(n=4-6)$.

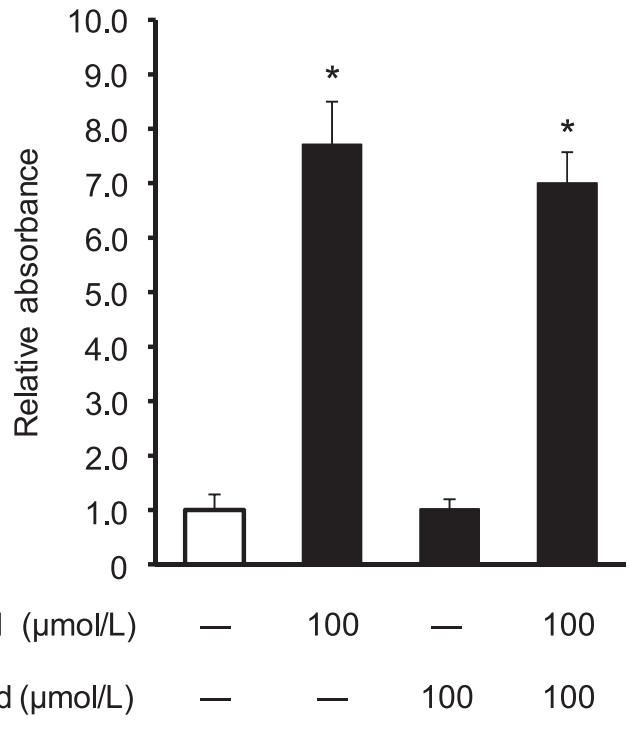

Fig. 4 Effect of oleanolic acid on octanoyl-CoA production. Absorbance is a surrogate index for the amount of acyl-CoA. The ratio of absorbance relative to the control (white bar) is shown. Values represent means $\pm \mathrm{SD}(\mathrm{n}=3) . * p<0.05$ vs. the control group.

of our study. Although $20 \mathrm{mg} / \mathrm{kg}$ of oleanolic acid decreased plasma octanoylated ghrelin level in our study, there is a possibility that 7 days administration of $10 \mathrm{mg} / \mathrm{kg}$ of oleanolic acid also reduces plasma octanoylated ghrelin level. Furthermore, de Melo et al. has reported that oleanolic acid increased plasma leptin level in mice ${ }^{14)}$. However, we speculate that in our study the change of plasma leptin level is minimal because the administration period of our study was shorter than that of de Melo et al., hence, there were no significant differences in cumulative food intake between control and oleanolic acid-treated mice in our study.

Oleanolic acid did not decrease plasma octanoylated ghrelin levels and body weight gain in high-fat diet-fed mice. Our previous study revealed that oleic acid decreases plasma octanoylated ghrelin levels in mice ${ }^{19)}$. Oleic acid is the most abundant fatty acid in the high-fat diet(D12451) used in this study. Furthermore, ingested medium-chain fatty acids are used directly for ghrelin acylation in mice ${ }^{20)}$. Dietary fatty acids after absorption are mostly present in an ester form. However, some fatty acids are thought to be de-esterified by esterase and form a conjugate with CoA. We consider that a part of oleic acid is also present as oleylCoA in the body of the mouse. Since acyl-CoA is known to be a substrate for acylation of ghrelin, oleyl-CoA may be involved in the inhibition of octanoylated ghrelin production. Therefore, the inhibitory effect of oleanolic acid on octanoylated ghrelin production might have been masked due to the suppression of octanoylated ghrelin production by oleic acid in the high-fat diet. D12451 contains various other fatty acids, and these may also compete with octanoic acid for acylation by GOAT, resulting in decreased octanoylated ghrelin. There is a report showing that plasma octanoylated ghrelin levels in high-fat diet-fed mice are lower than those in standard diet-fed mice ${ }^{14)}$, supporting our above-mentioned consideration.

Oleanolic acid did not decrease the plasma octanoylated ghrelin levels and body weight gain in high-glucose diet-fed mice as well as high-fat diet-fed mice. Glucose administration has also been reported to reduce plasma ghrelin levels ${ }^{21)}$. Therefore, the inhibitory effect of oleanolic acid 
on octanoylated ghrelin production may be masked by glucose in the high-glucose diet-fed mice as well as by fatty acids in high fat diet-fed mice.

Next, we investigated the mechanisms underlying the reduction in octanoylated ghrelin levels by oleanolic acid. We previously reported that (-) -epigallocatechin-3-O-gallate (EGCG) decreased plasma octanoylated ghrelin levels in mice, and decreased gene expressions of ghrelin and PC1/3 by EGCG may be involved in lowering the octanoylated ghrelin level ${ }^{22)}$. Therefore, we investigated the alteration of gene expressions of proteins related to octanoylated ghrelin production caused by oleanolic acid. In standard diet-fed mice, oleanolic acid did not affect the mRNA expression of ghrelin and enzymes such as GOAT, furin, $\mathrm{PC} 1 / 3$, or PC2, involved in octanoylated ghrelin production. In this study, we did not examine the effect of oleanolic acid on the enzymatic activities of GOAT, furin, PC1/3, and PC2. Oleanolic acid does not inhibit GOAT activity $^{23)}$, but its effect on other PC activities have not been evaluated. Further studies should investigate the effect of oleanolic acid on PC activities to elucidate the mechanism underlying the inhibition of octanoylated ghrelin production.

Our previous in vitro study showed that the carboxy group in triterpenes contributes to the suppression of octanoylated ghrelin production ${ }^{13)}$. Octanoyl-CoA, a substrate for GOAT, is formed by dehydrocondensation between the carboxy group in octanoic acid and the thiol group in CoA. If oleanolic acid forms a complex with CoA, the production of octanoyl-CoA may be competitively inhibited and decreased octanoylated ghrelin production may be induced. There was no significant difference in absorbance, a surrogate index for the amount of acyl-CoA, between groups treated with the combination of octanoic acid with oleanolic acid and octanoic acid alone. These data indicate that oleanolic acid did not affect the formation of octanoyl-CoA. For the detection of free fatty acids using the kit used in this study, it is essential to generate hydrogen peroxide and 2,3-trans-enoyl-CoA by the oxidation of acyl-CoA with acyl-CoA oxidase. Since there is no hydrogen neighboring the carboxy group in oleanolic acid, hydrogen peroxide is probably not produced, even if a complex of oleanolic acid and CoA is formed. Although absorbance was not increased by treatment with oleanolic acid in our study, it is not possible to conclude that a complex of oleanolic acid and CoA was not generated. The inhibitory effect of oleanolic acid on octanoylated ghrelin production may not be caused by the decrease in octanoyl-CoA.

Long chain fatty acids have been reported to decrease octanoylated ghrelin levels via the action on G-protein coupled receptor $120(\text { GPR120 })^{24)}$. Furthermore, cisplatin has been revealed to decrease octanoylated ghrelin levels via the action on $5-\mathrm{HT}_{2}$ receptor ${ }^{25)}$. It is necessary to investigate the involvement of GPR120 or 5- $\mathrm{HT}_{2}$ receptor-medi- ated mechanisms underlying the reduction of octanoylated ghrelin by oleanolic acid.

\section{CONCLUSION}

We demonstrated that oleanolic acid decreases plasma octanoylated ghrelin levels and body weight gain in standard diet-fed mice. Anti-obesity effects of triterpenes, such as oleanolic acid, have been reported in mice; therefore, the reduction of octanoylated ghrelin levels may contribute to the anti-obesity effect of oleanolic acid. Our findings may provide valuable knowledge for the development of anti-obesity agents with an inhibitory effect on octanoylated ghrelin production. The elucidation of the mechanism underlying the reduction of octanoylated ghrelin levels by oleanolic acid is a future issue.

\section{ACKNOWLEDGMENTS}

This work was supported by JSPS KAKENHI (Grant Numbers 15H06805 and 16K01848).

\section{CONFLICT OF INTEREST}

The authors declare no conflict of interest.

\section{REFERENCES}

1) Kojima, M.; Hosoda, H.; Date, Y.; Nakazato, M.; Matsuo, H.; Kangawa, K. Ghrelin is a growth-hormone-releasing acylated peptide from stomach. Nature 402, 656660 (1999).

2) Hosoda, H.; Kojima, M.; Matsuo, H.; Kangawa, K. Ghrelin and des-acyl ghrelin: two major forms of rat ghrelin peptide in gastrointestinal tissue. Biochem. Biophys. Res. Commun. 279, 909-913(2000).

3) Neary, N.M.; Druce, M.R.; Small, C.J.; Bloom, S.R. Acylated ghrelin stimulates food intake in the fed and fasted states but desacylated ghrelin has no effect. Gut 55, 135 (2006).

4) Tschop, M.; Smiley, D.L.; Heiman, M.L. Ghrelin induces adiposity in rodents. Nature 407, 908-913 (2000).

5) Asakawa, A.; Inui, A.; Kaga, T.; Yuzuriha, H.; Nagata, T.; Ueno, N; Makino, S; Fujimiya, M; Niijima, A; Fujino, M.A; Kasuga, M. Ghrelin is an appetite-stimulatory signal from stomach with structural resemblance to motilin. Gastroenterology 120, 337-345 (2001).

6) Yasuda, T.; Masaki, T.; Kakuma, T.; Yoshimatsu H. Centrally administered ghrelin suppresses sympathetic nerve activity in brown adipose tissue of rats. Neuro- 
sci. Lett. 349, 75-78(2003).

7) Al Massadi, O.; Tschop, M.H.; Tong, J. Ghrelin acylation and metabolic control. Peptides 32, 2301-2308 (2011).

8) Gutierrez, J.A.; Solenberg, P.J.; Perkins, D.R.; Willency, J.A.; Knierman, M.D.; Jin, Z.; Witcher, D.R.; Luo, S.; Onyia, J.E.; Hale, J.E. Ghrelin octanoylation mediated by an orphan lipid transferase. Proc. Natl. Acad. Sci. U. S. A. 105, 6320-6325 (2008).

9) Yang, J.; Brown, M.S.; Liang, G.; Grishin, N.V.; Goldstein, J.L. Identification of the acyltransferase that octanoylates ghrelin, an appetite-stimulating peptide hormone. Cell 132, 387-396 (2008).

10) Takahashi, T.; Ida, T.; Sato, T.; Nakashima, Y.; Nakamura, Y.; Tsuji, A.; Kojima, M. Production of n-octanoylmodified ghrelin in cultured cells requires prohormone processing protease and ghrelin $O$-acyltransferase, as well as n-octanoic acid. J. Biochem. 146, 675-682 (2009).

11) Zhu, X.; Cao, Y.; Voogd, K.; Steiner, D.F. On the processing of proghrelin to ghrelin. J. Biol. Chem. 281, 38867-38870 (2006).

12) Oiso, S.; Nobe, M.; Yamaguchi, Y.; Umemoto, S.; Nakamura, K..; Kariyazono, H. Establishment of a gastric cell-based assay system for exploring inhibitors of octanoylated ghrelin production. J. Biomol. Screen. 18, 1035-1042 (2013).

13) Nakajima, K.; Oiso, S.; Uto, T.; Morinaga, O.; Shoyama, Y.; Kariyazono, H. Triterpenes suppress octanoylated ghrelin production in ghrelin-expressing human gastric carcinoma cells. Biomed. Res. 37, 343-349 (2016).

14) de Melo, C.L.; Queiroz, M.G.; Fonseca, S.G.; Bizerra, A.M.; Lemos, T.L.; Melo, T.S.; Santos, F.A.; Rao, V.S. Oleanolic acid, a natural triterpenoid improves blood glucose tolerance in normal mice and ameliorates visceral obesity in mice fed a high-fat diet. Chem. Biol. Interact. 185, 59-65(2010).

15) Wellman, M.K.; Patterson, Z.R.; MacKay, H.; Darling, J.E.; Mani, B.K.; Zigman, J.M.; Hougland, J.L.; Abizaid, A. Novel regulator of acylated ghrelin, CF801, reduces weight gain, rebound feeding after a fast, and adiposity in mice. Front. Endocrinol. (Lausanne) 6, 144 (2015).

16) Kanellos, P.T.; Kaliora, A.C.; Gioxari, A.; Christopoulou, G.O.; Kalogeropoulos, N.; Karathanos, V.T. Absorption and bioavailability of antioxidant phytochemicals and increase of serum oxidation resistance in healthy subjects following supplementation with raisins. Plant Foods Hum. Nutr. 68, 411-415(2013).

17) Yin, M.C.; Lin, M.C.; Mong, M.C.; Lin, C.Y. Bioavailability, distribution, and antioxidative effects of selected triterpenes in mice. J. Agric. Food Chem. 60, 76977701 (2012).

18) Zhao, L.; Li, W.; Li, Y.; Xu, H.; Lv, L.; Wang, X.; Chai, Y.; Zhang, G. Simultaneous determination of oleanolic and ursolic acids in rat plasma by HPLC-MS: application to a pharmacokinetic study after oral administration of different combinations of QingGanSanJie decoction extracts. J. Chromatogr. Sci. 53, 1185-1192(2015).

19) Oiso, S.; Nobe, M.; Iwasaki, S.; Nii, W.; Goto, N.; Seki, Y.; Nakajima, K.; Nakamura, K.; Kariyazono, H. Inhibitory effect of oleic acid on octanoylated ghrelin production. J. Oleo Sci. 64, 1185-1192(2015).

20) Nishi, Y.; Hiejima, H.; Hosoda, H.; Kaiya, H.; Mori, K.; Fukue, Y.; Yanase, T.; Nawata, H.; Kangawa, K.; Kojima, M. Ingested medium-chain fatty acids are directly utilized for the acyl modification of ghrelin. Endocrinology 146, 2255-2264 (2005).

21) Shiiya, T.; Nakazato, M.; Mizuta, M.; Date, Y.; Mondal, M.S.; Tanaka, M.; Nozoe, S.; Hosoda, H.; Kangawa, K.; Matsukura, S. Plasma ghrelin levels in lean and obese humans and the effect of glucose on ghrelin secretion. J. Clin. Endocrinol. Metab. 87, 240-244(2002).

22) Nakajima, K.; Oiso, S.; Kariyazono, H. Inhibitory effect of $(-)$-epigallocatechin-3-O-gallate on octanoylated ghrelin levels in vitro and in vivo. Biol. Pharm. Bull. 41, 524-529 (2018).

23) McGovern-Gooch, K.R.; Mahajani, N.S.; Garagozzo, A.; Schramm, A.J.; Hannah, L.G.; Sieburg, M.A.; Chisholm, J.D.; Hougland, J.L. Synthetic triterpenoid inhibition of human ghrelin $O$-acyltransferase: the involvement of a functionally required cysteine provides mechanistic insight into ghrelin acylation. Biochemistry 56, 919-931 (2017).

24) Gong, Z.; Yoshimura, M.; Aizawa, S.; Kurotani, R.; Zigman, J.M.; Sakai, T.; Sakata, I. G protein-coupled receptor 120 signaling regulates ghrelin secretion in vivo and in vitro. Am. J. Physiol. Endocrinol. Metab. 306, E28-35 (2014).

25) Takeda, H.; Sadakane, C.; Hattori, T.; Katsurada, T.; Ohkawara, T.; Nagai, K.; Asaka, M. Rikkunshito, an herbal medicine, suppresses cisplatin-induced anorexia in rats via $5-\mathrm{HT}_{2}$ receptor antagonism. Gastroenterology 134, 2004-2013 (2008). 